\title{
SAFEGUARDING MARINE PROTECTED AREAS IN THE GROWING MEDITERRANEAN BLUE ECONOMY- RECOMMENDATIONS FOR THE MARITIME TRANSPORT SECTOR
}

\author{
M. RANDONE, M. BOCCI, C. CASTELLANI, C. LAURENT \& C. PIANTE \\ WWF Mediterranean Marine Initiative, Thetis Spa.
}

\begin{abstract}
Maritime transport is the backbone of the global economy. The sector is particularly important in the Mediterranean Sea which, despite covering less than $1 \%$ of the world's oceans, carries about $15 \%$ of global shipping. Worldwide, ocean-related economic activity - the so-called Blue Economy - is growing; and the maritime transport sector is expected to continue increasing at a rate of $4 \%$ per annum for the next decade. In line with the global expansion of seaborne trade, shipping activity in the Mediterranean is growing in terms of the number of routes, traffic intensity and size of ships. And with this growth come increasing environmental impacts, such as chemical pollution, noise pollution and collisions with marine mammals. These environmental impacts are an issue for the whole of the Mediterranean, but it's particularly critical that they're prevented - or at least minimized - in Marine Protected Areas (MPAs), which by definition are areas of great importance for marine biodiversity and ecosystems. In certain sensitive MPAs, maritime transport of any kind is forbidden. In many, though, shipping activity is legally possible, so there's an urgent need for all relevant stakeholders to work together to ensure sustainable transport practices and tools are identified and adopted to minimize its impact. Considering the growth of the sector, it's inevitable that major commercial traffic routes will increasingly interact with MPAs and other area-based conservation measures in some Mediterranean locations, especially where vessels are approaching ports or passing through straits. This paper provides key recommendations for the main actors in the maritime transport sector to help move towards a sustainable Mediterranean Blue Economy. The three stakeholder groups we focus on are MPA managers, public authorities and maritime transport companies. Each group has its own priorities, perspectives and powers, but all can make important contributions to a sustainable future for the region.

Keywords: biodiversity, blue economy, conservation, ecosystems, environmental impacts, marine protected areas, maritime transport, shipping.
\end{abstract}

\section{INTRODUCTION}

Maritime transport is one of the most important sectors of the Blue Economy, both globally and in the Mediterranean region. It includes the commercial transport of goods (bulk and non-bulk) and passengers (ferries), as well as land-based activities including industrial ports and the related facilities and services allowing vessels to access them. This is a growing sector, with vessels that have been getting larger and more specialised and with an increasing trend towards containerization and mass transport. From an environmental point of view, the impacts of this growth - in local and more general terms - are well documented. Oil spills and vessel strikes on endangered cetaceans are perhaps the most visible effects; but underwater noise, chemical contamination, alien species and seabed disturbance are also associated with the sector, and all affect MPAs conservation objectives. However, alongside these issues, targeted policies, technological progress and advances in science and research offer valuable opportunities for improving the situation.

Through the PHAROS4MPAs project, many examples of successful initiatives to resolve conflicts and mitigate environmental impacts have been gathered - in the Mediterranean and worldwide. By bringing together different stakeholders and exploring the major issues 
experienced in MPAs, this paper aims to provide examples and best practices to facilitate information exchange among MPAs affected by similar pressures, taking into account the different roles, interests and attitudes of MPA managers, public authorities and the maritime transport sector. To fulfil this objective, a set of recommendations on how public and private stakeholders in the Mediterranean can work to prevent - or minimize - the impacts of maritime traffic in Marine Protected Areas (MPAs), have been produced.

\section{HOW COMMERCIAL TRANSPORT ACTIVITIES AFFECT MPAS}

Maritime transport affects the marine environment both in the course of routine operations and through accidental events. Its impacts can be localized (e.g. the effects of anchoring or mooring) or far-reaching (e.g. underwater noise from ship engines); and they occur during offshore navigation as well as in coastal areas. Most of the region's MPAs and other effective area-based conservation measures (OECMs) are located in coastal and shallow areas. Mediterranean MPAs cover about $25 \%$ of the $0-15 \mathrm{~m}$ depth zone and almost $17 \%$ of the $0-50 \mathrm{~m}$ depth zone [1], it is therefore inevitable that major commercial traffic routes interact with MPAs and OECMs in some locations, especially when vessels are approaching ports or passing through narrow zones (e.g. straits).

Several MPAs and Natura 2000 sites along the Spanish Mediterranean coast (e.g. Cabo de Gata) for instance intersect with one of the busiest areas for large-tonnage maritime traffic [2]: this is one of the Mediterranean's most important Special Areas of Conservation for the bottlenose dolphin and the loggerhead turtle, so the risk of collisions is particularly serious. The Northern Adriatic ports also play a major role in liquid bulk transport. Italy handles one of the largest liquid bulk volumes in Europe (186 million tonnes [3]), but the accident frequency in the Adriatic Sea is five times the world average - this is due to the elongated shape of the basin, which means its long South to North oil route is frequently crossed by other commercial ships navigating between the Western and Eastern Adriatic coasts [4] [5]. As a result, oil pollution is an ever-present risk in the central and northern Adriatic, especially near main ports, potentially impacting the MPAs and Natura 2000 sites of the western and eastern coasts.

Only 5\% of the Mediterranean Sea is covered by MPAs and OECMs at depths greater than 200m [6]. The Pelagos Sanctuary for marine mammals is one example, being both the largest and the only pelagic MPA in the region. There are major commercial, touristic and industrial sites in the same area, and the resulting maritime traffic is one of the major pressures on the Sanctuary - an annual total of almost 4,000,000 km of vessel traffic from more than 80,000 transits by about 4,000 distinct vessels has been recorded [7]. The Sanctuary and the waters in and around the Gulf of Lion are particularly high-risk areas for ship strikes which have also been reported in Spanish and southern Italian waters [8] [9]. The Pelagos Sanctuary is intended to protect marine mammals from a variety of impacts, including physical disturbance, noise, collisions and chemical pollution (antifouling, hydrocarbons, other toxic compounds, macro-waste) [10], threatening the survival of many species [11].

Beyond MPAs and OECMs, there are larger areas extending far offshore where conservation measures and sustainable use practices should be adopted to protect cetaceans from maritime traffic, whether they are classed as critical cetacean habitat areas $(\mathrm{CCH})$ or important marine mammal areas (IMMAs) [12]. The Convention on Biological Diversity has also identified further Ecologically or Biologically Significant Areas (EBSAs) that support the healthy functioning of the Mediterranean Sea and the many services that it provides. All three of these classifications denote areas where protection is recommended but where there is no management in place. As the main crossroads between the western and eastern 
Mediterranean basins, the Strait of Sicily and the Tunisian Plateau are examples of areas of this kind. Their ecological value has been internationally recognized with the identification of two EBSAs and a possible IMMA [13]. Despite the fact that EBSAs, CCHs and IMMAs are not technically MPAs, they highlight areas of valuable and sensitive habitats, underlining the need for conservation measures. Large areas like these intersect almost all the major traffic routes of the Mediterranean.

\section{IMPACTS OF THE MARITIME TRANSPORT SECTOR ON MARINE ECOSYSTEMS}

Maritime transport affects the marine environment, both in the course of routine operations and through accidental events. Its impacts can be localized (e.g. the effects of anchoring or mooring) or far-reaching (e.g. underwater noise from ship engines); and they occur during offshore navigation as well as in coastal areas. The main impacts of maritime transport on marine ecosystems include: underwater noise, collisions with marine fauna, pollution from oil and other chemicals, seabed disturbance and introduction of alien species.

\subsection{Underwater noise}

The EU's Marine Strategy Framework Directive (2008/56/EC) directly addresses the introduction of noise into marine waters, stating that noise should be limited so that the marine environment is not adversely affected [14]. Establishing an MPA can be an effective way of reducing the impact of underwater noise - restrictions on maritime activities inside or even outside MPA borders can prevent noise spreading into critical areas [15]. While most research into the impact of underwater noise has focused on marine mammals, there's also increasing concern over what it may do to fish [16], aquatic birds and marine invertebrates [17] [18]. Underwater noise can change the behaviour of marine organisms, possibly impairing their hearing capacity, communication and ability to detect threats [15] [16]. Chronic exposure and cumulative effects, masking biological signals, can have long-term consequences for the conservation status of cetaceans, particularly in the most sensitive species [19]. Underwater noise hotspots in the Mediterranean overlap with several protected areas and/or with areas of importance to noise-sensitive marine mammal species. These include the Pelagos Sanctuary in the Ligurian Sea, the Strait of Sicily, parts of the Hellenic Trench, and the waters between the Balearic Islands and continental Spain [20].

\subsection{Collisions with marine fauna}

On a global scale, collisions with large vessels represent the main fatal threat for whales [21]. In the Mediterranean this is a serious conservation issue for fin whales (Balaenoptera physalus) and sperm whales (Physeter macrocephalus), especially in the western basin [22] [23] [24]. Ship strikes are made more likely by underwater noise, which can interfere with cetacean communication and prevent animals from detecting and reacting to threats. The Pelagos Sanctuary and the waters in and around the Gulf of Lion are particularly high-risk areas, and strikes have also been reported in Spanish and southern Italian waters [9] [17]. In the eastern basin, the Hellenic Trench southwest of Greece is a known area of high sperm whale density which is crossed by major shipping routes: the animals are at risk from ship strikes [25]. One study [9] analysed all documented ship strikes on fin whales in the Mediterranean Sea from 1972 to 2001 and found that out of the 287 recorded fin whales that have been hit during that 
period, 46 were confirmed to have died. Mortality was the highest in the last decade (1991-2002).

\subsection{Pollution from oil and other chemicals}

Oil spills are one of the most serious causes of marine pollution. They occur both in routine shipping operations (tank washing, loading/discharging, bunkering, dry-docking and discharging of bilge oil) and by accident. Oil tankers aren't the only vessels responsible: cargo ships, fishing boats and leisure craft all contribute to the overall pollution [17] [26] [27]. The Mediterranean has been considerably affected by oil spills. Since 1977 the total oil spillage has been approximately 310,000 tons, while the total spillage for other noxious substances has been $>120,000$ tons since 1988 [28]. Between 1970 and 2016 the region has experienced 14 accidental oil spills and 144,000 tons of crude oil was spilled in the biggest Mediterranean single discharge, the MT Haven accident off Genoa (1991) [27]. While major sea routes and the areas around key oil terminals are clearly most at risk, serious accidental oil spills could occur anywhere in the Mediterranean. Potential hotspots include the Ionian Sea, the Adriatic Sea, the Messina Straits, the Sicily Channel, the Ligurian Sea, the Gulf of Lion and the eastern part of Corsica [26]. The release of antifouling paints (Tributyltin (TBT) and its degradation products), oil and exhaust emissions, sewage and ballast waters, and marine litter are the main sources of shipping-related contamination in the Mediterranean.

\subsection{Seabed disturbance}

Maritime transport can cause general seabed disturbance which damages bottom habitats and species, especially when vessels are approaching shallow waters and ports. The anchoring and mooring of large vessels lead to abrasion and disturbance of bottom sediments [29], while there are extensive reports of the disturbance of soft sediments during navigation by the direct abrasion of ship hulls in shallow waters, propeller scarring and groundings [27]. In addition, when bottom sediments are physically disturbed water turbidity may increase: this can harm habitats of important conservation value (e.g. Posidonia oceanica). Most worldwide studies on the effects of anchoring and mooring have focused on seagrass beds and corals. Both are severely threatened by the mechanical action of anchors of vessels moored outside ports [30], although there is less evidence of how other species and habitats are affected [29]. Nevertheless, the anchoring and mooring of large vessels is likely to have a significant impact [30] [31].

\subsection{Introduction of alien species}

A steady rise in numbers of non-indigenous species introduced via shipping has been detected in all the Mediterranean basin, with a current rate (based on the last decade) of about one new species every six weeks [32]. According to the European Environmental Agency, shipping accounts for $51 \%$ of the introductions of non-indigenous marine species [33]. Ballast waters and hull fouling (when species attach to ships' hulls) are among the main vectors for these introductions, which can cause declines in abundance and local extinctions of native species [17]. Unfortunately, there are no regulations currently in place to manage hull fouling. However, the Ballast Water Management Convention entered into force in 2017 and establishes 
standards and procedures for managing ships' ballast water and sediments, aiming to prevent the spread of harmful aquatic organisms from one region to another.

\section{RECOMMENDATIONS FOR MEDITERRANEAN STAKEHOLDERS: PREVENT - OR MINIMIZE- IMPACTS OF THE MARITIME TRANSPORT SECTOR ON MPAS}

The recommendations provided in this section were formulated after a comprehensive review, involving both desk analyses and stakeholder engagement, of research outputs and best practices addressing the interactions between maritime transport on MPAs. Recommendations were derived from Mediterranean case studies, EU-funded projects, worldwide initiatives and other literature sources such as international guidelines (e.g. by IMO), scientific papers and technical reports. As expected, examples in the Mediterranean basin are found in wellknown areas of conflict, such as the Bonifacio Strait, that is the first Particularly Sensitive Sea Area in the Mediterranean, as well as in large MPAs, such as the Pelagos Sanctuary. However, less known areas of high environmental value offer other examples of good practices that are worth being valorised. Examples include Cabo de Gata (Spain), having repositioned the Traffic Separation Scheme contributing to the protection of the ecological value of the natural park and Côte Bleue Marine Park (France), that regulated the anchorage authorised areas also starting a dialogue with the Port Authority.

\subsection{Public authorities}

Public authorities can play a major role in preventing or minimizing the maritime transport sector's impacts on MPAs.

\subsubsection{National planning authorities}

National authorities planning and managing the use of sea space, including marine spatial planners, are key actors in identifying and implementing measures to avoid maritime sector impacts on ecosystems, particularly in relation to traffic accidents. National maritime authorities and conservation authorities can significantly contribute by defining ecosystem protection measures.

- Through Maritime Spatial Planning (MSP), authorities should make use of tools such as Particularly Sensitive Sea Areas (PSSAs), Areas To Be Avoided (ATBAs) and Traffic Separation Schemes (TSSs) to protect MPAs from the risks of maritime traffic accidents and reduce the chances of collisions with cetaceans. National authorities should coordinate monitoring programmes on marine mammal range and routes, to support MSP processes. In the case of transboundary MPAs, states should participate actively in the IMO and coordinate joint proposals for routeing systems and PSSAs.

- MSP processes can prevent anchoring impacts by introducing voluntary no-anchoring zones, adopting zoning plans indicating sensitive areas as well as suitable anchoring areas, and by including MPA boundaries and anchor-sensitive areas on nautical charts.

- Authorities should also introduce area-based regulations, such as banning the transit of dangerous goods in important marine areas to prevent severe accidents, or mandating the use of technical solutions to prevent collisions with cetaceans (e.g. real-time positioning systems). In addition, authorities should ensure the implementation of the Ballast Water Management Convention, particularly through inspections and monitoring activities.

- Joint cross-border actions need to be implemented for navigation monitoring and safety to 
ensure environmental impacts are avoided or minimized. These may include coordinated governance systems (a joint action plan) and innovative surveillance methods (e.g. new high-frequency radar antennae, data sharing, interoperability). Participation in coordinated response and contingency plans for oil spills and other pollution events at cross-border, sub-regional and regional levels is essential.

- Neighbouring states need to collaborate to establish MPAs on the high seas (e.g. under the Specially Protected Areas and Biological Diversity Protocol to the Barcelona Convention). These are necessary to protect sensitive marine areas that are not currently under the jurisdiction of national states, either due to the lack of an official EEZ or to uncertain navigational rights.

\subsubsection{Local authorities}

Local authorities (regions, provinces, municipalities etc, depending on national governance frameworks), local coastguards and port authorities can play a significant role in reducing the impact of maritime traffic. By running initiatives that complement actions put in place at state level, they can ensure that measures in force are implemented.

- Local authorities should collaborate with local maritime companies, identify and implement piloting solutions to avoid accidents in particularly sensitive areas. They should promote innovative procedures and technologies, such as collision avoidance devices.

- Port authorities should enforce international and national standards and requirements, for example through ship inspections. Coordination mechanisms involving port authorities and port states such as the Mediterranean MoU are particularly useful in order to avoid 'ports of convenience' in the region.

- Coastguards should use innovative procedures, tools and technologies, such as risk assessment and spills modelling, to reduce the risks and mitigate the impacts of oil spills. In addition, they should support and promote the establishment of volunteer rescue and cleaning patrols and rescue centres. Coastguards should also patrol MPAs regularly and ensure the compliance of ships through enforcement actions such as board-and-search and even arrest.

- Local authorities need to collaborate with MPA management bodies to develop joint solutions - including monitoring, modelling and vulnerability assessments - to monitor the impact of maritime traffic and mitigate the impact of pollution from port operations.

\subsubsection{Regional Governance}

Regional ocean governance mechanisms such as the Barcelona Convention can contribute to safeguarding MPAs from the impacts of navigation. They do this through a variety of tools including regional protocols and action plans; while also providing guidance to the contracting parties on the impacts of maritime transport and potential mitigation strategies.

- From the regulatory perspective, stronger enforcement and compliance mechanisms should be established for relevant legal frameworks. These include the Protocol Concerning Cooperation in Preventing Pollution from Ships and, in Cases of Emergency, Combating Pollution of the Mediterranean Sea and the Protocol on the Prevention of Pollution in the Mediterranean Sea by Transboundary Movements of Hazardous Wastes and their Disposal.

- Regional governance mechanisms should also be used to further support the designation of the Mediterranean as an Emission Control Area, particularly for nitrogen and sulphur 
oxides, to the benefit of all marine ecosystems in the region. They can facilitate increased engagement by regional states, and underpin the development of proposals to the IMO as part of MARPOL Annex VI.

- The implementation of ecosystem-based marine and coastal planning tools, such as MSP and ICZM, should be prioritized across the whole region. All Mediterranean countries should ratify and implement the ICZM Protocol, as this will support ecosystem-based planning processes which consider all possible interactions within an ecosystem, including the potential environmental risks related to maritime traffic activities. The ICZM Protocol should integrate a regional framework for ecosystem-based MSP.

- Regional governance mechanisms in collaboration with national authorities should promote the further development of transboundary oil spill contingency plans, early warning systems and decision support systems. These tools are much needed in the region, particularly in maritime transportation hotspots such as the Aegean Sea, the Adriatic and the Sicily Channel/Tunisian Plateau. Regional governance mechanisms can foster collaboration among countries to develop such tools.

- Coordinated regional initiatives aiming to increase surveillance at sea, using aerial surveys and radar satellite imagery, also represent important means of avoiding and controlling spills in the Mediterranean region.

\subsection{MPA Managers}

MPA management bodies rarely have the power to regulate maritime traffic: this is generally left to public authorities. However, case studies show that MPA managers can influence public decisions on preventing and minimizing impacts from maritime traffic. Proactively establishing a dialogue with the maritime transport sector is crucial: this may lead to agreements on more sustainable technologies and good navigation practices. In some instances, MPA managers can take local actions, such as identifying and implementing measures to regulate navigation and anchoring, environmental monitoring and research, reporting violations of regulations, education and awareness-raising.

With the objective to prevent or minimize impacts on marine ecosystems, MPA managers should:

- Collect data and increase knowledge about the impacts and risks of maritime traffic. These datasets represent the basis for impact avoidance measures.

- Advocate within planning and management processes - such as maritime spatial planning and integrated coastal zone management - for the establishment of specific spatial measures aimed at preventing accidents (e.g. establish a PSSA).

- Collaborate with the regional and sub-regional MPA manager networks (MedPAN, ADRIAPAN) in order to raise a stronger advocacy voice in the overall management of maritime transport, e.g. by organizing specific thematic sessions in the relevant regional forums and events, or by developing regional reports and policy briefs.

- Create local MPA networks aiming to enhance coordination in large protected areas (national or international) like the Pelagos Sanctuary.

- Advocate for practical solutions for impact avoidance at local level to competent actors, or directly implemented if under the competence of the MPA authority.

- Develop agreements with public authorities to introduce local regulations such as navigation and anchoring restrictions. Monitoring and reporting on national and international regulations are fundamentally important actions to ensure compliance. 
- Collaborate in developing contingency plans and intervention protocols to mitigate impacts of oil spill from accidents is a priority.

- Train citizens and other actors to clean up oil pollution in the field in case of accidents.

- Collect data and spread knowledge on the impact of contamination from maritime traffic and port activities on MPAs, including ecosystem functioning, pollution retention capacity and vulnerability.

With the objective to increase knowledge on impacts from maritime traffic, and to contribute to training and awareness raising, MPA managers should:

- (Co-)Design, run or participate in monitoring programmes and research studies to increase knowledge on the interactions between MPAs and the maritime transport sector, and its impacts on habitat and species.

- Collaborate with research/public institutions to develop new tools and technologies to avoid or mitigate the impact of the sector on MPAs.

- Develop agreements with the sector to engage trained observers on vessels for monitoring and research purposes.

- Offer best practice training programmes to shipping companies (e.g. speed reduction, prevention of collisions with cetaceans, reduction of underwater noise).

- Engage people in citizen science and participatory monitoring programmes.

\subsection{Maritime Transport Companies}

Shipping companies already have access to a variety of knowledge and technological solutions to minimize their impacts on the marine environment - and putting in place environmentally friendly practices has clear benefits for corporate image. Nevertheless, despite the legislation and policies currently in place, more dialogue is needed between the maritime transport industry and MPAs in order to reduce potential impacts and to identify potential solutions.

To contribute to prevent or minimize impacts on marine ecosystems, companies should:

- Develop agreements with MPAs on the protection of marine macrofauna such as in the case of La Meridionale, a Maritime Transport Company, that signed a charter of ecoresponsibility for its ferry service crossing the Pelagos Sanctuary and other MPAs in France.

- Respect national legislation concerning real-time cetacean positioning systems or detection technologies. All companies should train their staff in spotting and reporting cetaceans during navigation.

- Adopt best available technology to avoid or at least minimise marine and atmospheric pollution emissions, to improve waste management, and to avoid waste dispersion at sea.

- Collaborate with MPAs and research institutions for monitoring and research purposes.

- Adopt best available technologies - based on IMO Guidelines and others (e.g. AQUO project results) - to minimize underwater noise, including ship power requirements, propeller and machinery design (e.g. reducing cavitation, wake and propulsion improvement devices, reduction of machinery noise).

- Adopt best operational and navigation practices to minimize underwater noise, including operation of propellers, trims, acoustic emissions, propeller cleaning, underwater hull surface smoothing, selection of ship speed, and re-routeing. 


\section{CONCLUSIONS}

Maritime transport is particularly important for the Mediterranean economy, where the sector is growing in terms of the number of routes, traffic intensity and size of ships. With this growth come increasing environmental impacts, such as chemical pollution, noise pollution and collisions with marine mammals. Considering the growth of the sector, it is inevitable that major commercial traffic routes will increasingly interact with Mediterranean MPAs and other areabased conservation measures. Shipping activities with the most serious potential environmental impacts - such as the transport of dangerous goods or hydrocarbons - should be avoided altogether in Mediterranean MPAs. Where there are unavoidable interactions between maritime traffic and protected areas - such as in MPAs near ports and straits, or in larger MPAs like the Pelagos Sanctuary, solutions to avoid or mitigate impacts do exist, and all relevant actors, such as MPA managers, maritime transport businesses and public authorities should implement them in order to protect the precious marine resources of the Mediterranean region.

\section{ACKNOWLEDGEMENTS}

We would like to warmly thank all the people and organizations who were part of the advisory group of this publication or kindly contributed in some other way: Robert Turk and Tina Centrih Genov (Institute of the Republic of Slovenia for Nature Conservation), Amalia Alberini (WWF-Greece), Panagiota Maragou (WWF-Greece), Julien Le Tellier (UN Environment/MAP), Sylvain Petit (PAP/RAC), Gabino Gonzalez (REMPEC), Oscar Esparza (WWF-Spain), Theodora Papatheochari and Spyros Niavis (University of Thessaly), Atef Ouerghi (RAC/SPA), Wissem Seddik (MedPAN), Eric Charbonnel (Parc Marin de la Côte Bleue), Anthony Mastitski (WWF Mediterranean).

\section{REFERENCES}

[1] MedPAN, The 2016 Status of Marine Protected Areas in the Mediterranean, Main findings, 2016.

[2] Tejedor Arceredillo, A., Sagarminaga, R., de Stephanis, R., Cañadas, A. \& Lago, A., Management of MPAs: options and challenges for the maritime transport sector. Spanish case studies. Proceedings of the ECS/ASCOBANS/ACCOBAMS Workshop on Selection Criteria for Marine Protected Areas for Cetaceans. 2009.

[3] Eurostat. Maritime ports freight and passenger statistics, Statistics Explained http:// ec.europa.eu/eurostat/statisticsexplained/ -16/10/2018

[4] Med-Iamer Project. Maritime Transport Factsheet for the Adriatic-Ionian Ecoregion www.medmaritimeprojects.eu/download/ProjectMediamer/Final_factsheets/AIo_ Transport_factsheet.pdf, 2014.

[5] Thana, E. \& Patuzi, D., Toward a protected maritime environment of Adriatic Region. Mediterranean Journal of Social Sciences, 4(9), pp. 223-229, 2013.

[6] Fossi, M.C., Panti, C., Marsili, L., Maltese, S., Spinsanti, G., Casini, S., Caliani, I., Gaspari, S., Muñoz-Arnanz, J., Jimenez, B. \& Finoia, M.G., The Pelagos Sanctuary for Mediterranean marine mammals: Marine Protected Area (MPA) or marine polluted area? The case study of the striped dolphin (Stenella coeruleoalba). Mar Pollut Bull, 70(1-2), pp. 64-72, 2013.

[7] Coomber, F.G., D’Incà, M., Osso, M., Tepsich, P., Notarbartolo di Sciara, G. \& Moulins, A., Description of the vessel traffic within the north Pelagos Sanctuary: Inputs for Marine Spatial Planning and management implications within an existing international Marine protected area. Marine Policy, 69, pp. 102-113, 2016. 
[8] Abdulla, A. \& Linden, O., Maritime effects on biodiversity and potential mitigation measures. Chapter 5. In Maritime Traffic Effects on Biodiversity in the Mediterranean Sea, eds. A. Abdulla. \& O. Linden. Malaga, Spain: IUCN Centre for Mediterranean Cooperation, p. 184, 2008.

[9] Panigada, S.,Pesante, G.,Zanardelli, M., Capoulade,F., Gannier,A. \& Mason Weinrich,T., Mediterranean fin whales at risk from fatal ship strikes. Marine Pollution Bulletin, 52, pp. 1287-1298, 2006.

[10] Pelagos, Resoconto di decisioni della V conferenza delle parti contraenti all'Accordo Pelagos. PELAGOS_COP5_Doc20, 2013.

[11] Jacob, T. \& Ody, D., Characteristics of Maritime Traffic in the Pelagos Sanctuary and Analysis of Collisions Risk with Large Cetaceans, From the report of Quiet Oceans and Institut EcoOcéans, 2016.

[12] ACCOBAMS, www.accobams.org/conservationsaction/protected-areas/

[13] Notarbartolo di Sciara, G., Panigada, S., Lanfredi, C. \& Hoyt, E., Towards a Transboundary Managed Area in the Strait of Sicily: Challenges and Opportunities. Report to MAVA, Fondation pour l'Environnement, p. 85, 2017.

[14] EC, On criteria and methodological standards on good environmental status of Marine Waters, s.1.: Office Journal of the European Union, L232, pp. 14-24, 2010.

[15] Lüber, S., Frey, S. Prideaux, M. \& Prideaux, G., Creating 'quiet zones': Protecting Cuvier's beaked whale and Mediterranean monk seal critical habitat from anthropogenic noise in the Mediterranean Sea. Oceancare, Switzerland, 2015.

[16] Bracciali, C., Campobello, D., Giacoma, C. \& Sara', G., Effects of nautical traffic and noise on foraging patterns of Mediterranean Damselfish (Chromis chromis). PLoS ONE, 7(7), p. e40582, 2012.

[17] Abdulla, A. \& Linden, O., Maritime effects on biodiversity and potential mitigation measures. Chapter 5. In Maritime Traffic Effects on Biodiversity in the Mediterranean Sea Malaga, eds. Abdulla, A. \& Linden, O., Spain: IUCN Centre for Mediterranean Cooperation, p. 184, 2008.

[18] Azzellino, A., Lanfredi, C., D’Amico, A., Pavan, G., Podestà, M. \& Haun, J., Risk mapping for sensitive species to underwater anthropogenic sound emissions: Model development and validation in two Mediterranean areas. U.S. Navy Research, 2011.

[19] Maglio, A., Soares, C., Bouzidi, M., Zabel, F., Souami, Y. \& Pavan, G., Mapping shipping noise in the Pelagos Sanctuary (French part) through acoustic modelling to assess potential impacts on marine mammals. Sci. Rep. Port-Cros National Park, 29, pp. 167-185, 2015.

[20] Maglio, A., Pavan, G., Castellote, M. \& Frey, S., Overview of the noise hotspots in the Accobams area. Part I-Mediterranean Sea. Final report. https://oceancare. org/ wp-content/uploads/2016/07/ Report_L\%c3\%a4rm_Maglio-et-al_ Noise-Hot-Spots_ EN_2016.pdf, 2016

[21] IWC, Cates, K., Demaster, R.L., Silber, G., Gende, S., Leaper, R., Ritetr, F, \& Panigada, S. (eds.), Strategic Plan to mitigate the impacts of ship strikes on cetacean population: 2017-2020, 2017.

[22] David, L. \& Alleaume, G.C., Evaluation of the potential of collision between fin whales and maritime traffic in the north-western Mediterranean Sea in summer, and mitigation solutions. Journal of Marine Animals and Their Ecology, 4(1), pp. 17-28, 2011.

[23] Lewis, T., Boisseau, O., Danbolt, M., Gillespie, D., Lacey, C., Leaper, R., Matthews, J.N., McLanaghan, R. \& Moscrop, A., Abundance estimates for sperm whales in the Medi- 
terranean Sea from acoustic line-transect surveys. Journal of Cetacean Research and Management, 2017.

[24] Notarbartolo di Sciara, G. Sperm whales, Physeter macrocephalus, in the Mediterranean Sea: A summary of status, threats, and conservation recommendations. Aquatic Conserv: Mar. Freshw. Ecosyst, 24(Suppl. 1), pp. 4-10, 2014.

[25] Frantzis, A., Leaper, R., Paraskevi, A. \& Lekkas, D., Distribution patterns of sperm whales in relation to shipping density in the Hellenic Trench, Greece. Paper presented to IWC Scientific Committee, Bled, Slovenia, 12-24 May 2014. SC/65b/HIM 07.

[26] Galdis, C., Ship-generated oil discharges and exhaust emissions in the Mediterranean basin: their distribution and impact Chapter 4. In Maritime Traffic Effects on Biodiversity in the Mediterranean Sea, eds, A. Malaga Abdulla. \& O. Linden. Spain: IUCN Centre for Mediterranean Cooperation, p. 184, 2008.

[27] Girin, M. \& Carpenter, A., Shipping and PIL transportation in the Mediterranean Sea. In Oil pollution in the Mediterranean Sea: Part I - The International Context, Hdb Env Chem, eds. Carpenter \& Kostianoy, 2017.

[28] REMPEC, Regional information system; Part c2, statistical analysis -alerts and accidents database. Regional Marine Pollution Emergency Response Centre for the Mediterranean Sea, 2011.

[29] Griffiths, C.A., Langmead, O.A., Readman, J.A.J. \& Tillin, H.M., Anchoring and Mooring Impacts in English and Welsh Marine Protected Areas: Reviewing sensitivity, activity, risk and management. A Report to Defra Impacts Evidence Group, 2017.

[30] Boudouresque, C.F., Bernard, G., Bonhomme, P., Charbonnel, E., Diviacco, G., Meinesz, A., Pergent G., Pergent- Martini C., Ruitton S. \& Tunesi L., Protection and Conservation of Posidonia Oceanica Meadows, RAMOGE and RAC/SPA publisher, Tunis, pp. 1-202, 2012.

[31] Roy D., Divetain, N., Bernard, G., Coquillard, Y., Bonhomme, P. \& Gravez, V., Prospection de trois systèmes de mouillage en rade d'Hyères-Analyse et recommandations pour une éventuelle installation en baie de Port-Cros. Parc national de PortCros \& GIS Posidonie, GIS Posidonie publ., Fr.: pp. 1-32, 1999.

[32] Zenetos, A., Gofas, S., Morri, C., Rosso, A., Violanti, D., Raso, J. G., ... \& Ballesteros, E. Alien species in the Mediterranean Sea by 2012. A contribution to the application of European Union's Marine Strategy Framework Directive (MSFD). Part 2. Introduction trends and pathways. Mediterranean Marine Science, [S.l.], 13(2), pp. 328-352, December 2012. ISSN 1791-6763.

[33] EEA, www.eea.europa.eu/data-and-maps/indicators/trends-in-marine-alien-species/ assessment 